\title{
Korelasi Antara Visual Analogue Scale (VAS) dan Peak Nasal Inspiratory Flow (PNIF) Sebelum dan Sesudah Septoplasti
}

\author{
Augustien Yuliet Tamus, ${ }^{1}$ M. Thaufiq S. Boesoirie, ${ }^{2}$ Nur Akbar Aroeman ${ }^{2}$ \\ ${ }^{1}$ Rumah Sakit Umun Daerah Maria Walanda Maramis Kabupaten Minahasa Utara Sulawesi Utara, ${ }^{2}$ Departemen \\ Ilmu Kesehatan Telinga Hidung Tenggorok Bedah Kepala dan Leher Fakultas Kedokteran Universitas \\ Padjadjaran/Rumah Sakit Dr. Hasan Sadikin Bandung
}

\begin{abstract}
Abstrak
Deviasi septum merupakan keadaan yang sering terjadi, bervariasi dari ringan yang tidak mengganggu sehingga deviasi septum berat yang dapat menyebabkan obstruksi hidung. Diagnosis obstruksi hidung sangat kompleks dan bervariasi, selain berdasarkan anamnesis dan pemeriksaan fisis juga diperlukan pemeriksaan penunjang untuk pengukuran obstruksi hidung. Skor obstruksi hidung dengan menggunakan visual analogue scale (VAS) merupakan salah satu parameter untuk menilai obstruksi hidung secara subjektif, sedangkan secara objektif dengan peak nasal inspiratory flow (PNIF). Penelitian ini bertujuan menganalisis korelasi antara visual analogue scale (VAS) dan peak nasal inspiratory flow (PNIF) sebelum dan sesudah septoplasti. Penelitian yang dilakukan adalah penelitian quasiexperimental pre and post test design, dengan pemilihan sampel secara consecutive sampling. Sampel penelitian diambil dari pasien yang datang ke Poliklinik THT-KL Fakultas Kedokteran Universitas Padjadjaran/Rumah Sakit Dr. Hasan Sadikin Bandung periode Mei 2013-Juni 2014 yang memenuhi kriteria inklusi. Hasil penelitian menunjukkan septoplasti memperbaiki gejala klinis pasien septum deviasi, didapatkan peningkatan nilai PNIF dan penurunan nilai VAS sesudah satu bulan dilakukan septoplasti. Simpulan, terdapat korelasi antara visual analogue scale (VAS) dan peak nasal inspiratory flow (PNIF) sebelum dan sesudah septoplasti. [MKB. 2015;47(3):186-91]
\end{abstract}

Kata kunci: Obstruksi hidung, peak nasal inspiratory flow, septum deviasi, septoplasti, visual analogue scale

\section{Correlation between Visual Anologue Scale (VAS) and Peak Nasal Inspiratory Flow (PNIF) Before and After Septoplasty}

\begin{abstract}
Septal deviation is a frequently found state that varies from minor without interferences to severe cases of septal deviation that can cause nasal obstruction. Diagnosis of nasal obstruction is very complex and varies based on the anamnesis and physical examination due to the fact that it also requires supports from nasal obstruction measurement results. Nasal obstruction severity is defined by using scores. Visual analogue scale (VAS) is one of the parameters used for assessing nasal obstruction subjectively while peak nasal inspiratory flow (PNIF) is used for objective assessment. This study aimed to analyze the correlation between VAS and PNIF before and after septoplasty. This was a quasiexperimental study with pre- and post- test design. Sampling was performed using consecutive sampling method. Sample was taken from patients who visited ORL-HNS clinic of Dr. Hasan Sadikin General Hospital Bandung in May 2013-June 2014 according to the inclusion criteria. The results showed that septoplasty improved the clinical symptoms in patients with septum deviation, increase PNIF score, and decrease VAS score after one month. In conclusions, there is a correlation between VAS and PNIF before and after septoplasty. [MKB. 2015;47(3):186-91]
\end{abstract}

Key words: Nasal obstruction, peak nasal inspiratory flow, septum deviation, septoplasty, visual analogue scale

Korespondensi: Augustien Yuliet Tamus, dr., Sp.THT-KL, Rumah Sakit Umun Daerah Maria Walanda Maramis Kabupaten Minahasa Utara Sulawesi Utara, mobile 082127389998, e-mail yuliettamus@yahoo.com 


\section{Pendahuluan}

Deviasi septum merupakan keadaan yang sering terjadi, bervariasi dari ringan yang tidak mengganggu, hingga deviasi septum berat yang dapat menyebabkan penyempitan hidung sehingga mengganggu fungsi fisiologis hidung dan menyebabkan komplikasi. ${ }^{1}$ Deviasi septum nasi didefinisikan sebagai bentuk septum yang tidak lurus di tengah sehingga membentuk deviasi ke salah satu rongga hidung atau kedua rongga hidungyang mengakibatkan penyempitan pada rongga hidung. ${ }^{2}$ Suatu deviasi septum dapat menyebabkan penyempitan pada satu ataupun kedua sisi hidung dan akan terjadi perubahan pola aliran udara pada proses bernapas dan akhirnya mengganggu fungsi organ pernapasan lainnya termasuk sinus paranasal. ${ }^{3}$

Bentuk septum normal adalah lurus di tengah rongga hidung, tetapi pada orang dewasa biasanya septum nasi tidak lurus sempurna di tengah. Angka kejadian septum yang benarbenar lurus hanya sedikit dijumpai, biasanya terdapat pembengkokan minimal atau terdapat spina pada septum nasi. Bila kejadian ini tidak menimbulkan gangguan respirasi maka tidak dikategorikan sebagai abnormal., ${ }^{2,4}$

Angka kejadian deviasi septum nasi yang dilaporkan sangat bervariasi. Di bagian THTKL Rumah Sakit Dr. Hasan Sadikin (RSHS) Bandung pasien septum deviasi yang dilakukan septoplasti pada tahun 2013 sampai Juni 2014 mencapai 33 pasien dengan keluhan terbanyak obstruksi hidung dan sakit kepala jika disertai rinosinusitis. Pernah dilaporkan di Brazil pada tahun 2004, insidensi deviasi septum nasi mencapai $60,3 \%$ dengan keluhan obstruksi hidung sebanyak 59,9\%. Pada tahun 1995, Min dkk. menemukan prevalensi deviasi septum nasi di Korea mencapai 22,38\% dari populasi, dengan penderita yang terbanyak adalah laki-laki. Pada tahun 2002, di Turki, Ugyur dkk. melaporkan $15,6 \%$ bayi baru baru lahir dengan persalinan normal mengalami deviasi septum nasi seperti yang dikutip Oliviera dkk. ${ }^{5}$

Deviasi yang cukup berat dapat menyebabkan obstruksi hidung yang mengganggu fungsi hidung dan menyebabkan komplikasi atau bahkan menimbulkan gangguan estetik wajah karena tampilan hidung menjadi bengkok. Penyebab obstruksi hidung dapat bervariasi dari berbagai penyakit dan kelainan anatomis. Salah satu penyebabnya dari kelainan anatomi yang terbanyak adalah deviasi septum nasi. Tidak semua deviasi septum nasi memberikan gejala obstruksi hidung. Gejala lain yang mungkin terjadi dapat berupa hiposmia, anosmia, epistaksis, dan sakit kepala. Untuk itu para ahli berusaha membuat klasifikasi deviasi septum nasi untuk memudahkan diagnosis dan penatalaksanaannya. ${ }^{2,4,6}$

Gejala obstruksi hidung dapat menurunkan kualitas hidup dan aktivitas penderita, khususnya pada penderita yang mengalami gangguan tidur. ${ }^{7}$ Beberapa penyebab klinis terjadi obstruksi hidung adalah deviasi septum, hipertrofi konka, kolaps katup, polip, sinusitis, hipertrofi adenoid, neoplasma, atresia koanal, rinitis alergika, rinitis vasomotor, dan benda asing di hidung. ${ }^{8}$ Tahanan kolom udara hidung merupakan 50\% dari keseluruhan tahanan kolom udara jalan napas. Rongga hidung merupakan suatu resistor sejajar pada jalan napas. Tiga komponen tahanan hidung terdiri atas vestibulum nasi, katup hidung, dan kavum nasi. $^{9,10}$

Diagnosis berdasarkan atas gejala obstruksi hidung sangat kompleks dan bervariasi, selain berdasarkan anamnesis dan pemeriksaan fisis juga diperlukan pemeriksaan penunjang untuk pengukuran obstruksi hidung. Skor obstruksi hidung dengan menggunakan visual analogue scale (VAS) merupakan salah satu parameter untuk menilai suatu obstruksi hidung secara subjektif yang sederhana dan dapat dilakukan di semua fasilitas kesehatan. Untuk menilai kualitas hidup pasien sebelum dengan sesudah septoplasti dapat digunakan SNOT-22 seperti penelitian yang dilakukan Satish dan Sreedhar ${ }^{11}$ di Bagian THT Bangalore pada 70 pasien sebelum dengan sesudah septoplasti, total skor SNOT22 berkurang setelah dilakukan septoplasti. Untuk itu diperlukan pemeriksaan penunjang yang dapat digunakan untuk mendiagnosis dan mengevaluasi gejala obstruksi hidung secara objektif, di antaranya peak nasal inspiratory flow (PNIF), rinomanometri, serta rinometri akustik. Rinomanometri dan rinometri akustik merupakan baku emas yang telah diakui secara internasional untuk menilai sumbatan hidung secara objektif, tetapi metode ini sangatkompleks, mahal, tidak tersedia di setiap institusi kesehatan, dan hanya dapat dipergunakan oleh operator terlatih. Peak nasal inspiratory flow (PNIF) digunakan untuk mengukur secara kuantitatif besarnya aliran udara pernapasan yang melalui hidung. Pemeriksaan ini mempunyai keuntungan karena harga pemeriksaan yang lebih murah, waktu yang singkat, dapat dilakukan di rumah, variabilitas yang rendah, dan tidak sulit untuk dikerjakan. Beberapa penelitian menunjukkan bahwa ketepatan diagnostiknya PNIF telah teruji dibanding dengan rinomanometri. ${ }^{11-12}$ 
Beberapa studi mendemonstrasikan korelasi yangbaikantaraPNIF danrinomanometri.Sebuah penelitian yang membandingkan rinomanometri dengan PNIF melaporkan korelasi yang baik dan bermakna secara statistik antara kedua metode ini $(p<0,001)$. Peneliti menyimpulkan bahwa PNIF adalah teknik yang mampu memberikan hasil baik, mudah dilaksanakan, dan menunjukkan korelasi yang baik terhadap rinomanometri. Perlu diperhatikan kerjasama yang baik dengan pasien dan keterampilan pemeriksa selama pemeriksaan berlangsung. Karena penggunaannya yang mudah maka alat ini dapat dipakai dalam praktik sehari-hari oleh klinisi termasuk oleh dokter anak. ${ }^{12,13}$

Penelitian yang dilakukan Teixiere dkk. ${ }^{14} \mathrm{di}$ Brazil mendapatkan peak nasal inspiratory flow (PNIF) yang signifikan pada obstruksi hidung $(p<0,001)$ dan korelasi positif antara PNIF dan VAS pada obstruksi hidung. Penelitian ini bertujuan menganalisis korelasi antara visual analogue scale (VAS) dan peak nasal inspiratory flow (PNIF) sebelum dengan sesudah septoplasti.

\section{Metode}

Penelitian yang dilakukan adalah penelitian quasiexperimental pre and post test design, dengan pemilihan sampel secara consecutive sampling. Sampel penelitian diambil dari pasien yang datang ke Poliklinik THT-KL FK Unpad/RS Dr. Hasan Sadikin Bandung periode Mei 2013Juni 2014 yang memenuhi kriteria inklusi.

Kriteria inklusinya pasien usia $\geq 18$ tahun yang didiagnosis septum deviasi berdasarkan anamnesis, pemeriksaan fisis THT-KL, dan nasoendoskopi. Pasien yang bersedia ikut dalam penelitian menandatangani persetujuannya (informed consent), bersedia datang pada evaluasi satu bulan pascaoperasi septoplasti. Kriteria eksklusi: pasien septum deviasi dengan keganasan saluran napas atas, pasien septum deviasi dengan riwayat penyakit jantung dan paru (asma dan PPOK), terdapat rinitis alergi dan infeksi saluran napas atas, serta pasien yang memiliki kelainan anatomi berat di daerah hidung dan laring.

Data awal dilaksanakan sebelum pasien menjalani septoplasti. Data awal yang diambil yaitu berupa anamnesis, VAS, PNIF, SNOT-22, pemeriksaan fisis THT-KL dan nasoendoskopi, serta pengisian kuesioner rinitis alergi yang telah terstandardisasi. Data yang selanjutnya diambil yaitu anamnesis, VAS, PNIF, SNOT-22, pemeriksaan fisis THT-KL, dan nasoendoskopi, sesudah septoplasti satu bulan. Analisis statistik yang dilakukan untuk perbandingan tingkat obstruksi hidung sebelum dengan sesudah septoplasti dengan pengukuran visual analogue scale (VAS) dan peak nasal inspiratory flow (PNIF). Terlebih dahulu dilakukan uji normalitas data dengan menggunakan Shapiro-Wilk. Jika data berdistribusi normal maka digunakan uji-t berpasangan, jika data tidak berdistribusi normal sehinggas dipergunakan Uji Wilcoxon. Untuk mengetahui korelasi antara PNIF dan VAS digunakan analisis korelasi rank Spearman. Kemaknaan hasil uji ditentukan berdasarkan hasil nilai $\mathrm{p} \leq 0,05$.

\section{Hasil}

Pada penelitian ini dilakukan perhitungan statistik pada 29 subjek penelitian. Total 29 subjek penelitian ini terdiri atas 22 orang lakilaki dan 7 orang perempuan. Distribusi subjek berdasarkan usia didapatkan usia $<20$ tahun berjumlah 3 orang, usia 20-29 tahun berjumlah 14 orang, dan usia $\geq 30$ tahun berjumlah 12 orang. Berdasarkan lokasi dari septum deviasi yang menurut Mladina dibagi atas 7 tipe, dikelompokkan menjadi anterior (tipe I-II) dan posterior (III-VII) didapatkan yang terbanyak adalah lokasi septum deviasi bagian anterior (Tabel 1).

Pada Tabel 2 dapat dilihat hasil pemeriksaan skor VAS dan nilai PNIF subjek yang didiagnosis septum deviasi. Semua subjek sesudah septoplasti, skor VAS mengalami penurunan, sedangkan nilai PNIF mengalami peningkatan.

Tabel 1 Karakteristik Subjek Penelitian

\begin{tabular}{lc}
\multicolumn{1}{c}{ Karakteristik } & $\begin{array}{c}\text { Jumlah } \\
\text { (n=29) }\end{array}$ \\
\hline Jenis kelamin & 22 \\
$\quad$ Laki-laki & 7 \\
$\quad$ Perempuan & \\
Usia (tahun) & 3 \\
$<20$ & 14 \\
$20-29$ & 12 \\
$\geq 30$ & \\
Lokasi septum deviasi & 16 \\
Anterior (tipe I-II) & 13 \\
Posterior (tipe III-VII) &
\end{tabular}


Tabel 2 Hasil Pemeriksaan Skor VAS dan Nilai PNIF

\begin{tabular}{lccc}
\hline \multirow{2}{*}{ Variabel } & \multicolumn{2}{c}{ Pengamatan } & Nilai p*) \\
\cline { 2 - 3 } & Sebelum & Sesudah & $<0,001$ \\
VAS & 7 & 2 & \\
Median & $6-8$ & $1-3$ & $<0,001$ \\
Rentang & & & \\
PNIF & 50 & 125 & \\
Redian & $40-70$ & $100-135$ & \\
\hline
\end{tabular}

Keterangan: *) berdasarkan Uji Wilcoxon

Berdasarkan atas hasil penelitian, koefisien korelasi rank Spearman sebelum VAS dengan PNIF -0,325 $(\mathrm{p}=0,086)$, koefisien korelasi rank Spearman sesudah VAS dengan PNIF 0,183 $(\mathrm{p}=0,341)$, koefisien korelasi rank Spearman turun VAS (seluruh subjek sesudah septoplasti skor VAS mengalami penurunan) dengan naik PNIF (seluruh subjek sesudah septoplasti nilai PNIF mengalami peningkatan) $0,022(\mathrm{p}=0,911)$ sehingga disimpulkan tidak ada korelasi skor VAS dan nilai PNIF sebelum dan sesudah septoplasti.

Berdasarkan atas hasil penelitian, koefisien korelasi rank Spearman VAS dengan PNIF sebelum septoplasti terdapat korelasi negatif $\left(r_{s}=-0,325 ; p=0,043\right)$ yang artinya semakin naik VASS semakin turun PNIF, sedangkan sesudah septoplasti tidak terdapat korelasi. Selanjutnya, dengan mengorelasikan penurunan VAS dan juga peningkatan PNIF dengan dikontrol usia dan jenis kelamin diperoleh korelasi $r_{s}=0,356$ dan $\mathrm{p}=0,034$.

\section{Pembahasan}

Penyebab obstruksi hidung dapat bervariasi dari

\section{Tabel 3 Hasil Korelasi Nilai VAS dan Nilai PNIF Sebelum dengan Sesudah Septoplasti}

\begin{tabular}{lcc}
\hline \multicolumn{1}{c}{ Variabel } & rs & Nilai $\mathbf{p}^{*}$ ) \\
\hline VAS dengan PNIF & & \\
$\quad$ Sebelum & $-0,325$ & $0,043^{*}$ \\
$\quad$ Sesudah & 0,183 & 0,341 \\
$\begin{array}{l}\text { Penurunan VAS dengan } \\
\text { kenaikan PNIF** }\end{array}$ & 0,356 & 0,034 \\
\hline
\end{tabular}

Keterangan: rs: koefisien korelasi rank Spearman; *) uji 1 pihak; ${ }^{* *}$ ) setelah dikontrol oleh usia dan jenis kelamin berbagai penyakit dan kelainan anatomis. Salah satu penyebab kelainan anatomi yang terbanyak adalah deviasi septum nasi. Deviasi septum nasi yang memberikan gejala obstruksi hidung yang berat dan gejala lain yang mengganggu kualitas hidup dapat ditatalaksana dengan cara mengoreksi septum melalui septoplasti. Saat ini dikenal berbagai teknik septoplasti, antara lain septoplasti tradisional atau yang sering disebut septoplasti konvensional, septoplasti endoskopi, dan teknik open book septoplasty. Teknik septoplasti konvensional masih sering dipergunakan dan masih memberikan hasil yang baik.

Berdasarkan hasil perhitungan analisis statistik pada Tabel 1 didapatkan 29 subjek penelitian, terdiri atas 22 orang laki-laki dan 7 orang perempuan. Pada penelitian yang dilakukan Mondina dan Marro, ${ }_{15}^{15}$ juga didapatkan laki-laki lebih banyak daripada perempuan yang dilakukan septoplasti. Pada penelitian Mondina dan Marro, didapatkan sebanyak $64 \%$ laki-laki dan $36 \%$ perempuan, akan tetapi perbedaan jenis kelamin tidak memengaruhi hasil tindakan septoplasti baik pada laki-laki maupun pada perempuan. Pada tahun 1995, Min dkk. seperti yang dikutip oleh Oliviera dkk. ${ }^{5}$ menemukan prevalensi deviasi septum nasi di Korea mencapai $22,38 \%$ dari populasi dengan penderita yang terbanyak adalah laki-laki.

Distribusi subjek penelitian berdasarkan usia didapatkan tertinggi pada kelompok usia 20-29 tahun berjumlah 14 orang dan usia $\geq 30$ tahun berjumlah 12 orang. Hal ini sesuai dengan penelitian yang dilakukan Jain dkk. ${ }^{16}$ didapatkan pada dekade ke-2 dan ke-3. Pada penelitian ini rentang usia subjek penelitian bila dibandingkan antara kelompok usia didapatkan usia rata-rata subjek penelitian 30,9 tahun. Hasil ini tidak jauh berbeda dengan penelitian yang dilakukan Ascanio dan Manzini ${ }^{17}$ yang menunjukkan 
usia produktif seseorang untuk melanjutkan pendidikan dan mencari pekerjaan sehingga perlu dilakukan tindakan intervensi berupa septoplasti.

Berdasarkan lokasi septum deviasi menurut Mladina dibagi atas 7 tipe, dikelompokkan menjadi anterior (tipe I-II) dan posterior (IIIVII) didapatkan yang terbanyak adalah lokasi septum deviasi bagian anterior sebanyak 16 orang, sedangkan posterior 13 orang. Keadaan ini sesuai dengan penelitian yang dilakukan Janardhan dkk. ${ }^{19}$ bahwa lokasi septum deviasi bagian anterior yang menyebabkan obstruksi hidung karena berhubungan erat dengan katup hidung, sedangkan bagian posterior memegang peranan penting terjadi obstruksi hidung yang dapat menyebabkan rinosinusitis. Kompleks osteomeatal berperan penting dalam patogenesis rinosinusitis. Kompleks osteomeatal terdiri atas ostium sinus maksilaris, sel serta ostium sinus etmoid anterior, infundibulum, hiatus semilunaris, dan meatus media. Sumbatan itu menyebabkan pengecilan ostium sinus sehingga aliran udara dan mukus menjadi terhambat, serta mukus menjadi stasis.

Pada Tabel 2 terlampir hasil pemeriksaan nilai VAS dan nilai PNIF sebelum dan sesudah septoplasti berdasarkan Uji Wilcoxon sangat bermakna $(p<0,001)$. Hal ini sesuai dengan penelitian Yepes-Nunez dkk. ${ }^{19}$ yang menilai VAS dan PNIF pada subjek dengan obstruksi hidung. Hal ini juga sesuai dengan penelitian yang dilakukan Teixeira dkk. ${ }^{20}$ yang memperlihatkan penilaian obstruksi hidung menggunakan VAS dan PNIF pada subjek sebelum dan sesudah penggunaan dekongestan hidung (oxymetazoline chloride 0,05\%).

Pengukuran obstruksi hidung menggunakan visual analogue scale (VAS) merupakan salah satu parameter untuk dapat menilai obstruksi hidung secara subjektif yang sederhana dan dapat dilakukan di semua fasilitas kesehatan. Penurunan VAS sebanding dengan penurunan gejala obstruksi hidung, sedangkan PNIF akan berbanding terbalik dengan VAS, sesudah septoplasti penurunan gejala obstruksi hidung akan diikuti dengan nilai PNIF yang meningkat. Obstruksi dapat unilateral dan dapat pula bilateral sebab pada sisi deviasi terdapat konka hipotrofi, sedangkan pada sisi sebelahnya terjadi konka yang hipertrofi sebagai akibat mekanisme kompensasi. Septum deviasi juga dapat menyebabkan kolaps katup hidung (nasal valve). Katup hidung adalah celah antara ujung kaudal kartilago lateral atas dan septum hidung. Katup hidung berada lebih kurang 1,3 cm dari nares dan merupakan segmen yang tersempit serta tahanan terbesar dari jalan napas hidung. Dengan memasuki daerah yang sempit ini akan terjadi peningkatan aliran dan peningkatan tekanan interlumen (fenomena Bernoulli). Peningkatan tekanan akibat deviasi septum akan menyebabkan segmen ini kolaps pada saat inspirasi. PNIF merupakan alat untuk mengukur aliran udara hidung saat inspirasi karena daerah katup hidung ini sempit maka dengan perubahan sumbatan atau edema sedikit saja yang akan meningkatkan tahanan pada daerah tersebut. Pada penelitian yang dilakukan oleh Samsudin dkk. pada subras Deutero Melayu ditemukan bahwa rentang nilai PNIF untuk subjek laki-laki normal adalah 80-200 L/menit dengan ratarata $123 \mathrm{~L} /$ menit dan SD $22 \mathrm{~L} /$ menit. Untuk subjek perempuan normal, rentang nilai PNIF 80-140 L/menit dengan rata-rata $96 \mathrm{~L} /$ menit dan SD 18 L/menit. Pada Tabel 2 sesudah satu bulan dilakukan septoplasti didapatkan rentang nilai PNIF 100-135 L/menit yang hampir sama dengan nilai normal pada penelitian yang dilakukan Samsudin dkk.

Pada Tabel 3 diperlihatkan korelasi VAS dan PNIF sebelum dengan sesudah septoplasti. Hal ini sesuai dengan penelitian yang dilakukan Teixeira dkk. ${ }^{11}$ yang memperlihatkan korelasi antara VAS dan PNIF pada obstruksi hidung. Pada penelitian ini bukan pada subjek sebelum dengan sesudah septoplasti, melainkan pada subjek sebelum dengan sesudah penggunaan dekongestan hidung (oxymetazoline chloride 0,05\%). ${ }^{13}$ Pada pasien sesudah septoplasti didapatkan peningkatan nilai PNIF dan juga penurunan nilai VAS. Disarankan juga untuk pengukuran PNIF yang dibandingkan dengan alat ukur yang lebih spesifik seperti rinomanometri (keterbatasannya rinomanometri tidak tersedia di Indonesia) dan dilakukan penelitian lanjutan untuk evaluasi yang lebih lama dan berkala terhadap tingkat keberhasilan septoplasti secara subjektif dan objektif .

Simpulan penelitian, terdapat korelasi antara visual analogue scale (VAS) dan peak nasal inspiratory flow (PNIF) sebelum dan sesudah septoplasti.

\section{Daftar Pustaka}

1. Nizar W, Mangunkusumo E. Kelainan septum. Dalam: Soepardi E, penyunting. Buku ajar ilmu kesehatan telinga, hidung, tenggorok, kepala dan leher. Edisi ke-6. Jakarta: Gaya Baru Press; 2007. hlm. 126-7. 
2. Walsh WE, Korn RC. Sinonasal anatomy, function, and evaluation. Dalam: Bailey BJ, Johnson JT, penyunting. Head and neck surgery otolaryngology. Edisi ke-4. Philadelphia: Lippincott Williams \& Wilkins; 2006. hlm. 307-34.

3. Chmielik LP. Nasal septum deviation and conductivity hearing loss in children. BorgisNew Med. 2006;3:82-6.

4. Seyhan A, Ozaslan U, Azden S. Threedimentional modeling of nasal septal deviation. Annal Plast Surg. 2008;60(2):15761.

5. Oliviera AKP, Junior EE, Santos LV. Prevalence of deviated nasal septum in Curitiba, Brazil. Int Arch Otorhinolaryngol. 2005;9:288-92.

6. Zhang G, Solomon P, Rival R, Fenton RS, Cole P. Nasal airway volume resistance to airflow. Am J Rhinol. 2008;22(4):371-5.

7. Morris LG, Burschtin O, Lebowitz RA, Jacobs JB, Lee KC. Nasal obstruction and sleepdisordered breathing: a study using acoustic rhinometry. Am J Rhinol. 2005;19(1):33-9.

8. Gehani NC, Houser SM. Septoplasty, turbinate reduction and correction of nasal obstruction. Dalam: Bailey BJ, Johnson JT, penyunting. Head and neck surgeryotolaryngology. Edisi ke-5. Philadelphia: Lippincott Williams \& Wilkins; 2014. hlm. 612-9.

9. Samuel LJ, Danahey DG. Nasal aerodynamics. Emedicine [diunduh 13 Februari 2011]. Tersedia dari: http://emedicine.medscape. com/article/874822-overview

10. Skadding GK, Lund VJ. Investigative rhinology. London: Taylor \& Francis; 2004.

11. Satish HS, Sreedhar KT. Septoplasty outcome using SNOT-22 questionnaire study. IOSR J Dental Med Sci. 2013;6(5):34-8.

12. Papachristou A, Bourli E, Aivazi D, Futzila E, Papastavrou T, Konstandinidis T, dkk.
Normal peak nasal inspiratory flow rate values in Greek children and adolescents. Hippokratia. 2008;12(2):94-102.

13. Cunha IC, Sarinho ESC, Camargos PAM, Andrade CR, Filho AAS. Allergic rhinitis: epidemiological aspects, diagnosis and treatment. J Brasilian Pneumol. 2008;34(4): 230-40.

14. Teixeire RU, Zappelini CE, Alves FS, da Costa EA. Peak nasal inspiratory flow evaluation as an objective method of measuring nasal airflow. Braz J Otorhinolaryngol. 2011;77(4): 473-80.

15. Mondina M, Marro M. Assessment of nasal septoplasty using NOSE and RhinoQoL questionnaires. Eur Arch Otorhinolaryngol. 2012;269(10):2189-95.

16. Jain L, Jain M, Chouhan AN, Harswardhan R. Convensional septoplasty verses endoscopic septoplasty: a comperative study. people's. J Sci Research. 2011;4(2):24-8.

17. Ascanio LD, Manzini M. Quick septoplasty: Surgical technique and learning curve. Aest Plast Surg. 2009;33(6):814-8.

18. Janardhan RJ.Classification of nasal neptal deviations-relation to sinonasal pathology. Indian J Otolaryngol Head Neck Surg. 2005; 57:199-201.

19. Yepes-Nuñez JJ, Bartra J, Muñoz-Cano R, Sánchez-López J, Serrano C, Mullol J, dkk. Assessment of nasal obstruction: correlation between subjective and objective techniques. Allergologia Immunopathologia. 2013;41(6):397-401.

20. Teixeira RUF, Zappelini CEM, Oliveira LG, Basile LCG, Costa EA. Correlation between the peak nasal inspiratory flow and the visual analogue scale before and after using a nasal decongestant. Int Arch Otorhinolaryngol. 2011;15(2):156-62. 